\title{
Solid waste management in Asian countries: problems and issues
}

\author{
A. Khajuria ${ }^{1}$, Y. Yamamoto ${ }^{2} \& \mathrm{~T}$. Morioka ${ }^{2}$ \\ ${ }^{I}$ Division of Sustainable Energy and Environmental Engineering, \\ Graduate School of Engineering, Osaka University, Osaka, Japan \\ ${ }^{2}$ Graduate School of Engineering, Osaka University, Osaka, Japan
}

\begin{abstract}
Asia has been experiencing very high population growth and urbanization. Asian countries will witness a large population increase, which will have important implications for a variety of urban environmental issues, such as solid waste management. Nowadays, waste management is a major challenge in Asian countries, as it creates environmental problems. The present study reveals the problems and issues of solid waste management in Asian countries and certain important problems and issues that must be addressed in order to achieve public cooperation. At the core of the problems of solid waste management are the absence of adequate policies, enabling legislation, and an environmentally stimulated and enlightened public. This paper aims to identify parameters that help to explain the present situation and to assess the future amount of municipal solid waste (MSW) generated per capita in different Asian countries and how to develop an effective waste management strategy for Asian countries according to economic level.
\end{abstract}

Keywords: solid waste, population growth, GDP per capita, waste generation, urban growth rate, management of solid waste.

\section{Introduction}

The problem of solid waste management has acquired an alarming dimension in developing countries during recent decades. The quantity of solid waste generated has increased significantly and its characteristics have changed as a result of the change in peoples' lifestyles due to swift urbanization. Fast population growth and economy increase activities, and this combined with a 
lack of training in modern solid waste management practices complicates the efforts to improve the solid waste service (Bhide and Sudersan [1]).

Solid waste management is the major problem being faced by country municipalities because it involves a huge expenditure and receives scant attention by ISWA and UNEP [2]. It is not only a technical problem but it is also strongly influenced by political, legal, socio-cultural, environmental and economic factors, as well as available resources. Moreover, these factors have interrelationships that are usually complex in waste management systems (Kum et al., [3]). A SWM practice is a subject of concern for public health and environmental protection agencies in most developing countries. Compared to high income countries, the urban residents of developing countries produce less per-capita solid waste, but the capacity of the developing countries to collect, process, dispose or reuse it in a cost effective way is limited.

Developing Asian countries face serious problems in managing their solid waste. The annual waste generation increases in proportion to the rise in population and urbanization, and issues related to disposal have become challenging as more land is needed for the ultimate disposal of these solid wastes (Schubeler [4]). Solid waste is normally disposed of in an open dump in Asian towns and cities, which is not the proper method of disposal because such crude dumps pose environmental hazards causing ecological imbalances with respect to land, water and air pollution (Technobanoglous et al., [5]). Increasing population levels, rapid economic growth and rising community living standards will accelerate the future MSW generation rate within Asian countries.

The wastes generated by human settlements and the associated problems are similar in developing nations with variances between regions and locations based on geographic, socio-cultural, industrial, infrastructure, legal and environmental factors (Stern et al., [6]). This paper highlights the issues and the changing scenario of the MSWM in five Asian developing countries, viz. India, Nepal, Pakistan, Bangladesh and Sri Lanka. The present study reveals the problems and issues of solid waste management in Asian countries and certain important problems and issues that must be addressed in order to achieve public cooperation.

\section{Methodology}

\subsection{Calculation of population}

The population is calculated by Weber [7].

\subsubsection{Equation 1}

$$
\mathrm{P}(1+\mathrm{r})^{\mathrm{T}}
$$

where $\mathrm{P}=$ initial population people, $\mathrm{r}=$ percent growth rate $/ 100$ and $\mathrm{T}=$ years.

\subsection{Calculation of waste}

The waste generation per capita was calculated according to Weber [7]. 


\subsubsection{Equation 2}

$$
\text { (P) } x(\text { WGR }) \times(\text { No.d } / y) \div(\text { No.p/t) }
$$

where $\mathrm{P}=$ population, $\mathrm{WGR}=$ waste generation rate, No. $\mathrm{d} / \mathrm{y}=$ number of day per year and No. pond $/ \mathrm{t}=$ number of ponds per tons.

\subsection{Calculation of GDP}

GDP per capita is the gross domestic product divided by midyear population. GDP is the sum of value added by all resident producers in the economy plus any product taxes (less subsidies) not included in the valuation output. It is calculated without making deductions for depreciation of fabricated capital assets or for depletion and degradation of natural resources. Value added is the net output of an industry after adding up all the outputs and subtracting intermediate outputs by the World Bank [8].

\section{Results and discussion}

\subsection{Status of urban population refers to solid waste in Asian developing countries}

The urban population has witnessed rapid increases of $10.64,6.5,14.15,23.16$ and $27.07 \%$ in 2001 and the future growth of the urban population is estimated to be nearly $12.32,8.71,15.00,25.77$ and $28.70 \%$ in 2010 and $14.28,11.53,15.92$, 28.71 and $15.92 \%$ in 2030 in the developing countries of India, Nepal, Pakistan, Bangladesh and Sri Lanka respectively. It is anticipated that by 2025, about 52 percent of Asians would be living in urban areas causing a major shift in the distribution of the population as well as the expansion of the urban boundaries (Census of India [9]). The significant increase in the urban population is shown in fig. 1, this increase puts greater pressure on the partially existing MSWM infrastructure, as shown in similar studies by Brinkhoff [10] and the Nepal Census [11].

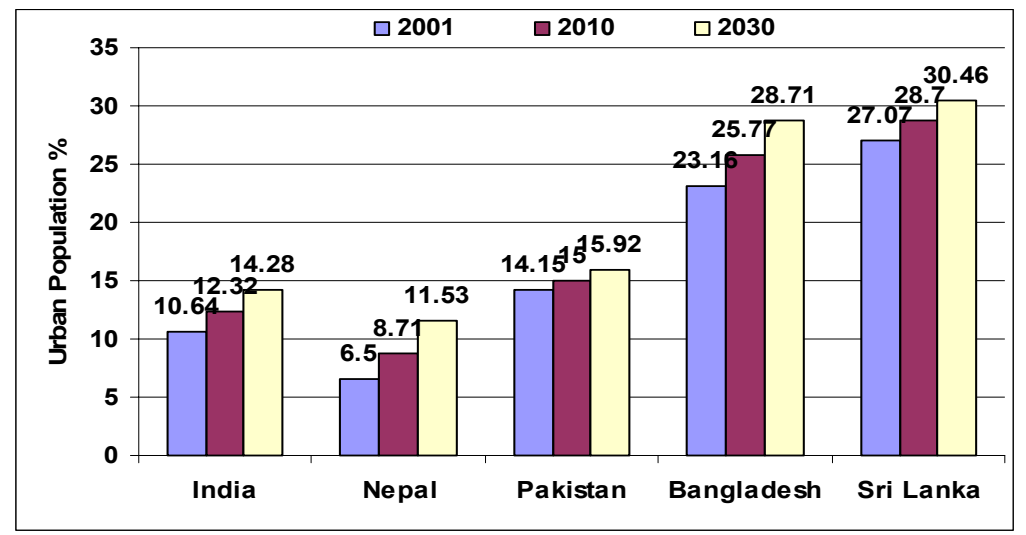

Figure 1: $\quad$ Present and future population prediction in Asian countries. 
The above data show the minimum population increase in comparison to the other study countries. The economic growth increase has improved the standard of living of urban citizens and created a higher per capita waste generation rendering the existing MSWM system ineffective and at risk of massive failure.

\subsubsection{Status of India}

Increasing urbanization in India is part of the global trend with 10.64 percent of India's population of the total 1075 million living in urban areas (as per the 2001 census). A number of towns and cities have increased populations ranging between 5000 and 20,000. The number of metropolitan cities having a population of one million plus has increased to $10.64 \%$ as per the 2001 census, $12.32 \%$ as per future census 2010 , and $14.28 \%$ in 2030 respectively (fig. 1), the census also defines the similar observation by Brinkhoff [10] and the Nepal Census [11]. The amount of MSW has gradually increased, which causes an adverse impact on the environment and human health.

\subsubsection{Status of Nepal}

The major pressure on waste management in Nepal is urbanization, which is characterized by rapid and haphazard growth. Nepal is predominantly a rural country with only $15 \%$ of the population living in urban areas (municipalities with a population of over 9000). However, it has the fastest growing urban population with a growth rate of $6.5 \%$ per annum, which is the highest in Asia. Between 1991 and 2001 the total municipal population grew by $77 \%$. The urban population is witnessing a rapid increase of $8.71 \%$ as per the 2010 census and $11.53 \%$ as per the 2030 census (fig. 1), the official government also defines a similar trend in the Nepal Census [12].

\subsubsection{Status of Pakistan}

In Pakistan, the urban population was around 14.15\% during the 2001 census and as per future censuses it will be $15.00 \%$ in 2010 and $15.92 \%$ in 2030. During the last several decades, migration has occurred from rural to urban areas. The settlements account for about 25 to $30 \%$ of Pakistan's overall urban population (fig. 1). The municipal institutions do not have sufficient resources and technical capacity to accommodate the needs of the increasing urban population; the government of Pakistan also confirm this statistical data in the Pakistan Census [13]. Pakistan's cities currently average only 50 percent of the waste quantities generated. The increased quantity of waste will also place greater demands on disposal services, thereby exacerbating an already poor situation since present disposal methods for solid waste are totally inadequate. Disposal is by open dumping, primarily on flood plains and into ponds, causing significant environmental damage.

\subsubsection{Status of Bangladesh}

Solid waste management is an obligatory function of Urban Local Bodies in Bangladesh. With over 3.3\% annual growth in the urban population in Bangladesh during 1991-2001 census years; 25.77\% in the 2010 census and $28.71 \%$ in the 2030 census respectively (fig. 1), solid waste generation has also increased proportionately with the growth of the urban population. The bureau of 
Bangladesh also defines similar trends of urban population in the Bangladesh Census [14]. As such, most of the urban local bodies are finding it difficult to keep pace with the demand for adequate solid waste management. Lack of financial resources, institutional weakness, improper choice of technology and lack of public awareness about solid waste management has rendered solid waste management services far from satisfactory.

\subsubsection{Status of Sri Lanka}

Sri Lanka is a country of some $65,610 \mathrm{sq} \mathrm{km}$ and a population of 91.96 million urban people in 2001; 112.01 million in 2010 and 136.56 millions in 2030 respectively. The population density of Sri Lanka is one of the densest in Asia, at 298 persons $/ \mathrm{sq} \mathrm{km}$. The urban population is witnessing a rapid increase of $28.70 \%$ in 2010 and $30.46 \%$ in 2030 respectively, similar observations were found in the Sri Lanka Census [15]. The significance of this increase in the urban population can be seen in fig. 1. In Sri Lanka, MSW has become a critical environmental issue, with increasing waste generation, and changing composition of the waste stream with more inorganic waste. The final disposal is predominantly open dumping leading to increasing environmental degradation and growing health problems.

\subsection{Waste quantity in Asian countries}

The solid waste quantities are estimated to increase from 26, 15, 24, 57 and 91 million tons in 2001; 32, 24,33,77 and 112 million tons in 2010 and 39, 40, 44, 104 and 136 million tons in 2030 in India, Nepal, Pakistan, Bangladesh and Sri Lanka respectively, the MSW quantity were also determined by Dhussa and Varshney [16], Lopez [17] and McConnell [18]. In respect of GDP the waste quantity of the study countries were found in India to be 0.66 in 2001, 0.80 in 2010, 0.98 in 2030; in Nepal to be 0.27 in 2001, 0.44 in 2010, 0.72 in 2030; in Pakistan to be 0.33 in 2001, 0.44 in 2010, 0.59 in 2030; in Bangladesh to be 0.55 in 2001, 0.73 in 2010, 1.01 in 2030 and in Sri Lanka to be 0.49 in 2001, 0.60 in 2010 and 0.73 in 2030 respectively (fig. 2).

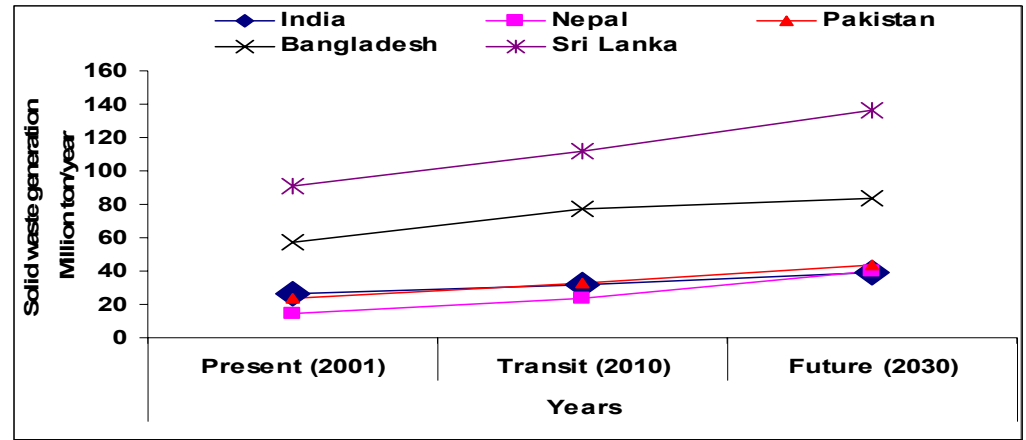

Figure 2: MSW generation millions tons/year (present-transit-future-phase) in developing Asian countries. 
According to the World Bank report, in 1995 GDP per capita was about 490 US dollars with $27.8 \%$ urban population, generating about $0.64 \mathrm{~kg} / \mathrm{capita} /$ day of MSW and it further increases, in 2025 , to about $48.8 \%$ of urban population with a high income GDP of about 1050US dollars, due to this correlation, a waste amount of about $0.6-1.0 \mathrm{~kg} / \mathrm{capita} /$ day is estimated in the study of developing countries by the World Bank [19]. Visvanathan and Trankler [20] and Grossman and Krueger [21] have carried out a correlation between the Asian countries they describe due to a rapid increase in urban population with about 35 percent of the total population residing in urban areas. It is anticipated that by 2025 , about 52 percent of Asians would be living in urban areas causing a major shift in the distribution of the population as well as the expansion of the urban boundaries.

The solid waste generation is based on the size of the urban population, density of population, economic development and consumption rate of commercial goods. The per capita generation of solid waste in the study countries is given in fig. 3 , which indicates a range of $0.66,0.27,0.33,0.55$ and $0.49 \mathrm{~kg}$ per capita in $2001 ; 0.80,0.44,0.44,0.73$ and $0.60 \mathrm{~kg}$ per capita in 2010 and $0.98,0.72,0.59,1.01$ and $0.73 \mathrm{~kg}$ per capita in 2030 respectively, due to the increase in the urban population (fig. 3), a similar study also observed by the Global and World fact sheet [22,23]. Minimum waste quantities in Nepal were found to be 0.27 to $0.72 \mathrm{~kg} /$ capita in future scenarios and the maximum waste quantity was found to be 0.66 to $0.98 \mathrm{~kg}$ /capita in 2010 to 2030 respectively (fig. 4). This is mainly due to economic disparity among the population. The urban population is over 38 percent and the waste generation has been increasing over the years.

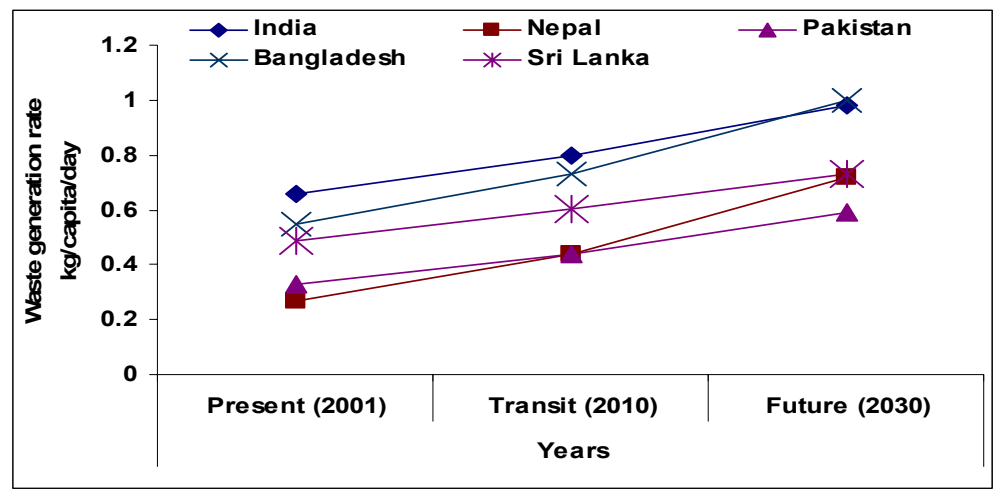

Figure 3: $\quad$ MSW generation $\mathrm{kg}$ /capita/day (present-transit-future phase) in developing Asian countries.

The per capita generation of solid waste in Asian cities also correlated between the ranges of 0.2 to $1.7 \mathrm{~kg}$ /day. This is based on the economic status and population density. The urban population is over 38 percent and the waste generation has been increasing over the years (China country report [24]). SW generation depending on per capita generation increases with the level of income 
of the family or individual. Figure 5 indicates that as every person in a developing country increases their income, so the solid waste increases in the same ratio.

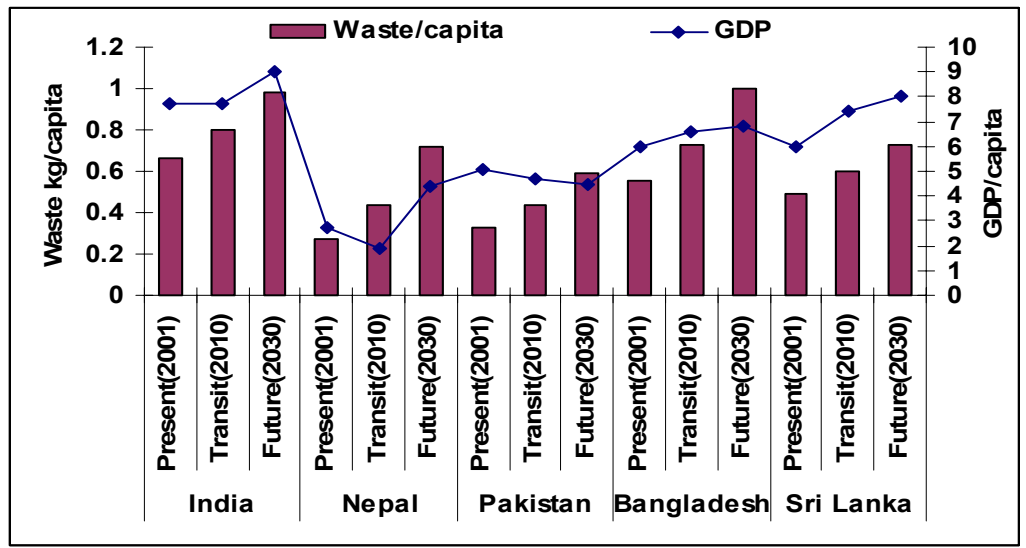

Figure 4: Correlation between GDP per capita and waste generation (present-transit-future phase) in Asian developing countries.

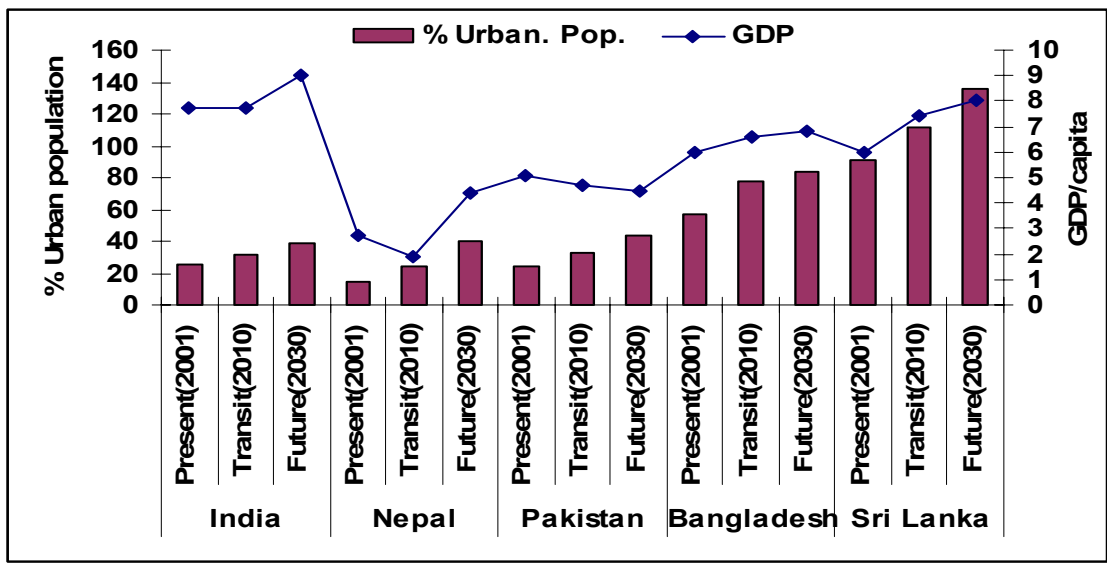

Figure 5: Correlation between GDP per capita and urban population (present- transit-future phase) in Asian developing countries.

\subsection{Composition of MSW in Asian developing countries}

The inter-connected factors that contribute to different patterns of waste composition are given in fig. 6. This waste characteristic is changing due to urbanization, increased commercialization and standard of living. In India, biodegradable and other waste (including wood, ash, inert material, stones, sanitary pads) have the highest composition in the present scenario at around 40- 
$42 \%$, whereas in 2010 and 2030, it will be decreased by around 5-10\%, the developed regions currently have a higher biodegradable content (World fact sheet [23]). The composition dictates the technology needed for waste processing prior to disposal. However, in Nepal, biodegradable (68\%) and plastic (12\%) composition increased in 2001, but in the years 2010 and 2030 the biodegradable material will be decreased and the plastic composition will be increased by around $14 \%$ due to the rapid increase in urbanization. In Pakistan, as in India, the biodegradable and other material is increased but in the future it will be decreased by $5-10 \%$ because we use the $3 \mathrm{R}$ technologies for proper scientific disposal methods. On other hand, in Bangladesh the present scenario is about $0.5 \%$ of metal composition, but in 2010 and 2030 it will be increased, though at present the percentage of biodegradable waste is high at around $70 \%$, it will be decreased by $10-15 \%$. In Sri Lanka in 2001, the present scenario is that the composition of biodegradable materials and paper is higher in proportion but in 2010 and 2030, biodegradable waste is decreased but paper waste is increased. In Nepal, plastic waste will increase, while a decrease will be seen in paper, glass and plastic due to the intensive collection and scavenging by informal waste collectors (NRI [25]). The present trend indicates that the paper and plastic contents will increase, due to the increasing trend for the use of plastic and paper - an impact of the progressing industrialization and urbanization with a growing GDP (Waters and Sanitation programme [26]). Due to a gradual change in life style, the economy is increased, the use of plastic and paper is increased, and MSW composition is also going to change.

The waste generation in India, Nepal, Pakistan, Bangladesh and Sri Lanka is due to increased consumption patterns as well as rapid urbanization and the rate of economic growth causes the higher value in waste generation per capita per day.

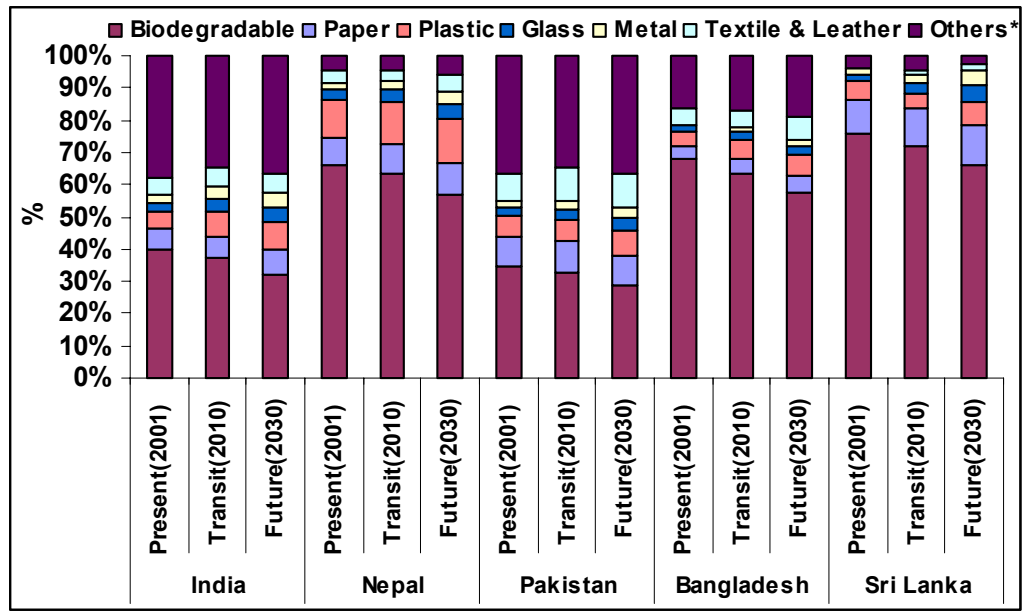

Figure 6: MSW composition (present-transit-future phase) in Asian developing countries. 


\subsection{MSW processing and disposal in Asian developing countries}

Proper disposal of MSW is a necessity to minimize environmental hazards and land degradation. In this regard, systematic disposal methods are necessary for safe disposal of MSW. In developing countries the following methods are used viz. composting, landfilling and incineration (Zurbrugg [27] and Enayetullah [28]). The most common disposal methods in the study countries indicate the share of open dumping to be $60 \%$ in India, $70 \%$ in Nepal, $80 \%$ in Pakistan, $95 \%$ in Bangladesh and $85 \%$ in Sri Lanka, in the present, and in the future $50 \%$ in India, $65 \%$ in Nepal, $75 \%$ in Pakistan, $85 \%$ in Bangladesh and $80 \%$ in Sri Lanka (fig. 7). The so-called landfill is mostly covering refuse in the dumpsite by soil neither with proper technical input nor with treatment of the emerging emissions to water, air and soil (Lizin [29] and World Bank [30]). In this way we recommended the $3 \mathrm{R}$ i.e. reuse, recycle and reduce method for minimizing the MSW in these developing countries.

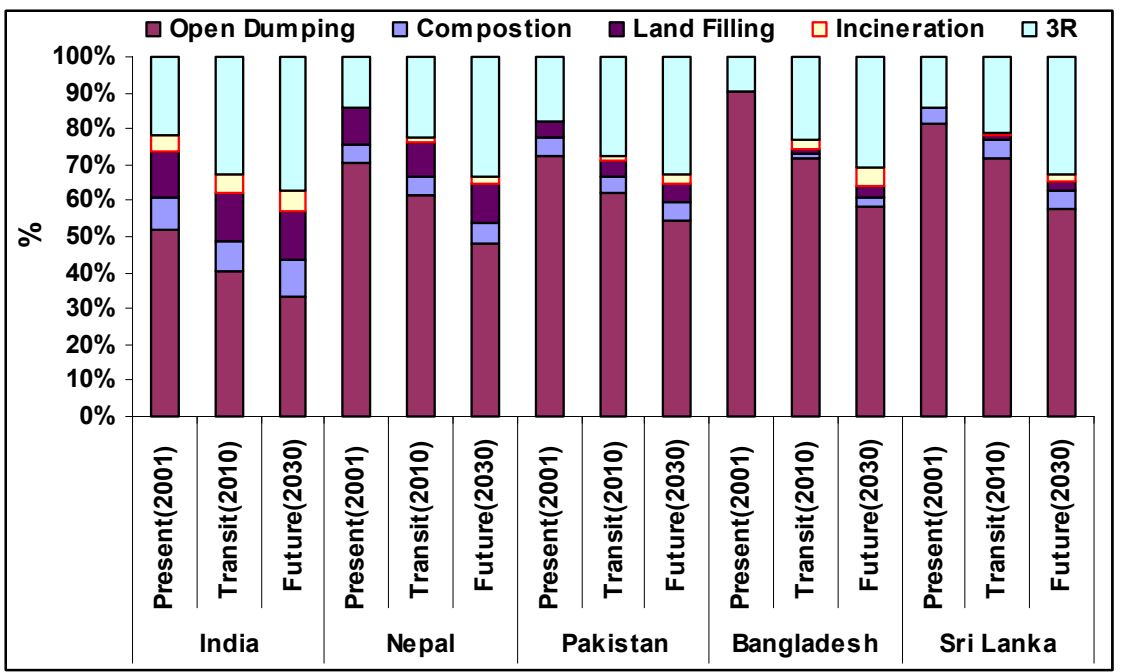

Figure 7: MSW disposal methods (present-transit-future phase) in Asian developing countries.

\section{Conclusion}

The study presents some current scenario of MSW, which will be useful for future planning and make effective strategies of MSW management in Asian developing countries; The presently adopted system i.e. collection, transportation and disposal is low-level, but in the future developed countries will adopt advanced technologies, when the MSWM is formalized. Solid waste generation is based on the economic development, density of population, size of the urban habitation and consumption rate of commercial goods. At present, the MSW 
collection scenario consists of different categories of waste items mixed together. The composition of MSW shows mostly organic matter, so, vermi-composting and composting are useful methods for treatment and production of soil amendment and useful for reduction of waste. The segregation of waste at source and the recycling and reuse of segregated material will reduce the quantity of waste and reduce the open dumping waste volume, while the 3Rs and vermicomposting need to be promoted in the public awareness, along with public private partnership, littering of waste, scientific disposal methods and after onsite/off-site recovery. The provided improvement strategies will in the future prevent health hazards and environmental impact.

\section{References}

[1] A.D. Bhide and B.B. Sundersan, Solid Waste Management in Developing Countries, Indian National Scientific Documentation Center, New Delhi, India, 1983.

[2] ISWA \& UNEP, Waste Management: Industry as a partner for sustainable development. International Solid Waste Association \& United Nations Environment Programme ISBN: 92-807- 2194-2, 2002.

[3] V. Kum, A. Sharp and N. Harnpornchai, Improving the solid waste management in phnom Pench city: a strategic approach, Journal of Waste Management 25 (1), pp. 101-109, 2005.

[4] Schubeler, P. Conceptual Framework for Municipal Solid Waste Management in Low-Income Countries, UNDP/UNCHS (Habitat)/ World Bank/SDC Collaborative Programme on Municipal Solid Waste management in Low-Income Countries, 1996.

[5] Technobanoglous, G., Theisen, H and Vigil, S. Integrated Solid Waste Management, 'Engineering Principles and Management Issues' McGraw Hill, Inc. New York. ISBN 0-07-06-3237-5, 1993.

[6] Stern, D. I., M. S. Common, and E. B. Barbier. Economic growth and environmental degradation: The environmental Kuznets curve and sustainable development. World Development 24 (7) pp. 1151-1160, 1996.

[7] Laura Weber, Developing Solid Waste Management Plans. St. Regis Mohawk Tribe. 2004. www.epa.gov/epaoswer/non-hw/tribal/pdftxt/dmg2.pdf - Similar pages

[8] World Bank. What a Waste: Solid Waste Management in Asia Urban Development Sector Unit East Asia and Pacific Region, May 1999. http://www.worldbank.org/html/fpd/urban/publicat/whatawaste.pdf as of September 2003.

[9] Census of India 2001, (Chapter 4), Series 1, 2001, http://mospi.nic.in/stat_pr.htm

[10] Brinkhoff, T., City population, 2005. http://www.citypopulation.de.

[11] Nepal, Ministry of Population and Environment, Demographic Situation. Retrieved from, 2002. http://www.unescap.org/esid/psis/population/5appc/ doc/Nepal_country_report.doc on 2 June 2007

[12] Nepal urban population census, http://www.populstat.info/Asia/nepalc.htm 
[13] Pakistan census, http://www.studentsoftheworld.info/pageinfo_pays.php3? Pays $=$ PAK\&Opt $=$ population

[14] Bangladesh population census, http://www.bbs.gov.bd

[15] Srilanka population census, http://www.studentsoftheworld.info/pageinfo pays.php3?Pays $=\mathrm{SRI} \& \mathrm{Opt}=$ population

[16] Dhussa A.K and Varshney A.K. Bio Energy News, 'Energy Recovery from Municipal Solid Waste - Potential and Possibility’, UNDP, 4(1): 2000.

[17] Lopez, R., The environment as a factor of production: The effects of economic growth and trade liberalization. Journal of Environmental Economics and Management 27, pp. 163-184, 1994.

[18] McConnell, K., Income and demand for environmental quality. Environment and Development Economics 2, pp. 383-399, 1997.

[19] World bank report, What a Waste: Solid Waste Management in Asia, The International Bank for Reconstruction and Development/THE WORLD BANK, 1818 H Street, N.W., Washington, D.C. 20433, U.S.A., 1999.

[20] C. Visvanathan and Trankler, J., Municipal Solid Waste Management in Asia: A Comparative Analysis. Workshop on Sustainable Landfill Management, 3-5 December, Chennai, India, pp. 3-15, 2003.

[21] Grossman G.M, and Krueger, A. B., Economic Growth and the Environment. The Quarterly Journal of Economics 110 (2), pp. 353-77, 1995.

[22] Global website, Population indicators. http:/globalis.gvu.unu.edu/ indicator_detail.cfm?Country $=\mathrm{LK} \&$ IndicatorID $=140 \#$ row

[23] World fact sheet, http://www.worldfactsandfigures.com/gdp_country_desc. php

[24] Country Report, National Research Institute (NRI), China. Municipal Solid Waste Management in China, 2003.

[25] National Research Institute (NRI), India. Municipal Solid Waste Management in India. Country Report, 2003.

[26] Water and Sanitation Program - South Asia. Profits from Waste: An NGOled Initiative for Solid Waste Management in Lucknow, Uttar Pradesh, India, 1999. http://www.wsp.org/pdf/sa-lucknow.pdf

[27] Zurbrugg, C. The Challenge of Solid Waste Disposal in Developing Countries, SANDEC News, EAWAG, No. 4, 1999.

[28] Enayetullah, I., “ A Study of Solid Waste Management for Environmental Improvement of Dhaka City. " an unpublished Master of Urban \& Regional Planning Thesis, Department of Urban \& Regional Planning, Bangladesh University of Engineering \& Technology (BUET), Dhaka, 1995.

[29] Lizin, A. M. City-to-City Networking to Fight Poverty published in the Choices Magazine, September, 2002, New York: UNDP, 2002.

[30] World Bank. Sectoral Analysis: Solid Waste Management. Washington D.C.: The World Bank, 1998. 